\title{
Gastrointestinal Fate of Emulsion-based $\omega-3$ Oil Delivery Systems stabilized by Plant Proteins: Lentil, Pea, and Faba bean Proteins
}

\author{
Cansu Ekin Gumus, Eric Andrew Decker, and David Julian McClements*
}

Department of Food Science, University of Massachusetts, Amherst, MA, 01003 USA

*Corresponding author:

David J McClements, mcclements@umass.edu, tel. +1-413-545-1019, fax. +1-413-545-1262

Room 330, Chenoweth Laboratory, Department of Food Science, University of Massachusetts, 102 Holdsworth Way, Amherst, MA, 01003 USA

Journal: Journal of Food Engineering

Submitted: February 2017 


\begin{abstract}
Functional foods are being fortified with bioactive lipids to improve human health. The formulation of these products from plant-based ingredients, rather than synthetic or animal-based ones, is often preferred by consumers. However, there is concern that encapsulation of bioactive lipids using plant-based ingredients may decrease their oral bioavailability. The aim of this study was to provide an understanding of the impact of plant-protein coatings on the gastrointestinal fate of omega-3 ( $\omega-3)$ oil droplets. A simulated gastrointestinal tract (GIT), including mouth, stomach and small intestine stages, was used to compare the gastrointestinal fate of lipid droplets coated by plant proteins (lentil, pea, faba bean proteins) with those coated by an animal protein (whey protein). All the emulsions behaved fairly similarly in the GIT model: the droplets were highly negative in the mouth and small intestine, but slightly positive in the stomach; extensive droplet aggregation occurred in the mouth and stomach; the droplets were digested in the small intestine. No significant differences in free fatty acids released in the small intestine were observed among the different systems, suggesting plant proteins did not inhibit lipid digestion and release.
\end{abstract}

Keywords: Omega-3 oils; fish oil; legume proteins; plant proteins; emulsions; natural emulsifiers; in vitro digestion 


\section{Introduction}

Eicosapentaenoic acid (22:5 omega-3, EPA) and docosahexaenoic acid (22:6 omega-3, DHA) are long-chain omega-3 polyunsaturated fatty acids (PUFAs) that are abundant in fish and algae oils (Lane et al., 2014; Lordan et al., 2011). A diet rich in omega-3 PUFAs may promote cardiovascular health and reduce inflammation, diabetes, cancer, asthma, schizophrenia, and depression (Lane et al., 2014; Lorente-Cebrian et al., 2013). Due to their high susceptibility to lipid oxidation and their low water-solubility, oil sources rich in omega-3 PUFAs are usually incorporated into colloidal delivery systems to protect them during processing, storage, and transport (Genot et al., 2013; Jacobsen, 2015). Emulsion-based delivery systems, which consist of emulsifier-coated lipid droplets dispersed within an aqueous medium, have been shown to be particularly suitable for this purpose because of their ease of preparation and flexibility of design (Mao and Miao, 2015; McClements, 2012). Many of the emulsifiers currently used in the food industry to stabilize emulsions are either synthetic (often esters of fatty acids) or animal-based (such as milk, egg, or meat proteins) (Kralova and Sjoblom, 2009). There is increasing demand from consumers for "clean label" products that are formulated from plant-based ingredients, and therefore there is interest in replacing synthetic or animal-based emulsifiers with plant-based ones in food emulsions (Lam and Nickerson, 2013; McClements and Gumus, 2016).

Pulses are a particularly good source of edible proteins because of their relative abundance, sustainable supply, and low cost (Boye et al., 2010). The Food and Agriculture Organization (FAO) of the United Nations describes pulses as the edible and dry seeds of legumes that are members of the Fabaceae or Leguminosae families which includes chickpeas, peas, lentils, beans, and lupins (FAO, 2016). Pulses have a good nutritional profile due to their low sodium, fat and cholesterol content, low glycemic index, and high protein, iron, folate, potassium and fiber content (Song et al., 2016). Plant proteins can be isolated from pulses using and converted into functional ingredients using commercially viable extraction and purification methods (Baiano, 2014). The major protein fractions in pulses are globulins (such as $7 \mathrm{~S}$ and $11 \mathrm{~S}$ ) and albumins, while the minor protein fractions are prolamins and glutelins (Marcone et al., 1998).

A potential disadvantage of pulse proteins is their lower digestibility in the gastrointestinal tract (GIT) compared to proteins from animal sources (Fernandez-Quintela et al., 1997). If pulse proteins are going to be utilized as emulsifiers in emulsion-based delivery systems, then it is important that they will release the encapsulated bioactive lipids within the GIT (McClements et al., 2007). Typically, the ingested triacylglycerols (TAGs) must be hydrolyzed by gastric and pancreatic lipases within the stomach and small intestine, which leads to the formation of free fatty acids (FFAs) and 
monacylglycerols (MAGs) (McClements et al., 2009; Singh et al., 2009). These lipid digestion products then interact with bile salts and phospholipids from the small intestinal secretions to form mixed micelles, which transport the FFAs and MAGs to the epithelium cells where they are absorbed (Wilde and Chu, 2011). The bioavailability of bioactive lipids could therefore be reduced if pulse protein-coated lipid droplets are not fully digested within the GIT. There have been relatively few previous studies on the potential gastrointestinal fate of lipid droplets coated by pulse-proteins. A recent study on the utilization of pea and soy proteins to coat conjugated linoleic acid (CLA) droplets indicated that only about $22-25 \%$ of the FFAs were released in a simulated GIT model (FernandezAvila et al., 2016). This result suggests that plant-proteins may suppress lipid digestion, which would be a major disadvantage for their application as delivery systems. An alternative explanation for the relatively low level of lipid digestion reported in this study is that the concentrations of gastrointestinal components used in the GIT model (e.g., digestive enzymes, bile salts, and calcium ions) did not adequately reflect human gastrointestinal conditions (Li et al., 2011). Another recent study reported that high concentrations of pea proteins in oil-in-water emulsions retarded the rate of $\beta$-carotene release under simulated GIT conditions, but this may have been because the high protein levels used promoted extensive droplet flocculation (Shao and Tang, 2016).

The main objective of the current study was therefore to determine the impact of three pulse protein emulsifiers (isolated from lentil, pea, and faba bean) on the digestibility of fish oil-in-water emulsions using a simulated GIT model. These three pulse proteins were selected because they are readily available commercial ingredients that can be used in the food industry. The impact of these plant-based proteins on lipid digestion was also compared to that of a widely-used animal-based protein (whey). Whey-protein coated lipid droplets have been shown to be readily digested within a simulated GIT (Qiu et al., 2015), and therefore serve as a good control. The results from this study should therefore provide valuable information about the potential utilization of pulse proteins to create emulsion-based delivery systems for bioactive lipids.

\section{Materials and Methods}

\subsection{Materials}

Pea, lentil, and faba bean concentrates (Vitessence Pulse 1550, 2550 and 3600) were provided by Ingredion, Inc. (Bridgewater, NJ). The composition of these three pulse protein ingredients provided by the supplier is summarized in Table 1. Fish oil was provided by DSM, Inc. (Columbia, MD). Whey protein isolate (BiPro JE 011-4-420) was provided by Davisco Foods International, Inc. (Le Sueur, MN). The manufacturer reported that this ingredient contained $94 \%$ protein, $0.3 \%$ fat, $0 \%$ carbohydrate, $0.67 \%$ sodium, $0.07 \%$ potassium, and $0.1 \%$ calcium, with the remainder being mostly 
moisture. The main components used in the simulated gastrointestinal model were: mucin (porcine stomach), gastric pepsin (porcine, 250 units/mg), pancreatic lipase (porcine, 100-400 units/mg), and bile extract (porcine), which were purchased from Sigma-Aldrich (St. Louis, MO). An aqueous sodium phosphate buffer $(10 \mathrm{mM}, \mathrm{pH}$ 7.0) was used to prepare all protein solutions and emulsions. All other chemicals and reagents used in this study were analytical grade and were purchased from Sigma-Aldrich (St. Louis, MO, USA).

\subsection{Protein purification}

The pulse protein concentrates provided by the manufacturer contained about $55-60 \%$ protein, and so a purification step was carried out before producing the emulsions. The protein purification protocol used was based on a method described previously with some modifications (Joshi et al., 2011). The protein concentrates were dispersed in buffer solutions by stirring for 2 hours at room temperature at $\mathrm{pH} 7.5$ at a concentration of $20 \%(\mathrm{w} / \mathrm{w})$. Then the solution was centrifuged (Sorvall Lynx 4000 Centrifuge, Thermo Scientific, Agawam, MA) at $15,000 \mathrm{~g}$ for 30 minutes at $10{ }^{\circ} \mathrm{C}$ to get remove any starch, fiber, and insoluble matter, including insoluble proteins. The supernatant was then collected and centrifuged again using the same conditions. The resulting supernatant was then collected in another beaker and the $\mathrm{pH}$ was adjusted to 4.5 using hydrochloric acid $(\mathrm{HCl})$ solution to promote isoelectric precipitation of the proteins. Solutions were then centrifuged again using the same conditions as described previously to precipitate and collect the proteins. The supernatant was removed and replaced with fresh buffer solution $(\mathrm{pH}$ 7.0). The precipitate was dispersed in buffer solution at room temperature for 60 minutes and the mixture was adjusted back to $\mathrm{pH} 7.0 \mathrm{using}$ sodium hydroxide $(\mathrm{NaOH})$ solution. To ensure complete dispersion, the protein solutions were stirred overnight at $5{ }^{\circ} \mathrm{C}$. The resulting solutions were brought to room temperature, stirred for 30 minutes, and then adjusted to $\mathrm{pH} 7.0$ and centrifuged again. The protein contents of the resulting solutions were determined by the Lowry method (Lowry et al., 1951) using a standard curve prepared with a bovine serum albumin standard $\left(\mathrm{R}^{2}=0.992\right)$. The protein solutions were then all adjusted to $20 \mathrm{mg} / \mathrm{mL}$ protein content using buffer solutions prior to emulsion formation so that they had similar protein levels.

\subsection{Emulsion formation}

Emulsions were prepared by homogenization of $10 \%(\mathrm{w} / \mathrm{w})$ oil phase (fish oil) and 90\% w/w aqueous phase (protein solution, pH 7.0) at ambient temperature. A high-shear mixer (M133/1281-0, Biospec Products Inc., Bartlesville, OK) was used to blend the two phases for 2 minutes at 10,000 rpm to produce coarse oil-in-water $(\mathrm{O} / \mathrm{W})$ emulsions. These emulsions were then passed through a high-pressure microfluidizer (PureNano, Microfluidics, Newton, MA) 3 times at 10,000 psi. This 
device contained a series of $\mathrm{X}$ - and Y-interaction chambers to breakdown the droplets, which were cooled throughout homogenization using an ice bath to prevent a rise in emulsion temperature. The conditions used to fabricate the emulsions in this study were based on those found to produce stable emulsions containing relatively small droplets in an earlier study using similar proteins (Gumus et al., 2017).

\subsection{In vitro digestion}

The gastrointestinal fate of the emulsions was monitored using a static simulated GIT that has been widely utilized in our laboratory (Waraho et al., 2011). Initially, the samples were diluted with buffer solution (1:5) to obtain a fat content of $2 \%$, since this level of fat is usually appropriate to give full digestion under the simulated GIT conditions used.

Mouth phase: $20 \mathrm{~mL}$ of the emulsions were mixed with $20 \mathrm{~mL}$ of artificial saliva solution containing $0.6 \mathrm{~g}$ mucin that was prepared according to previous studies (McClements and Li, 2010; Ozturk et al., 2015; Sarkar et al., 2009a). The mixture was then adjusted to pH 6.8 and incubated at $37^{\circ} \mathrm{C}$ for 10 minutes with continuous agitation at $100 \mathrm{rpm}$ (Innova Incubator Shaker, Model 4080, New Brunswick Scientific, New Jersey, USA).

Stomach phase: Simulated gastric fluid stock solution (SGFSS) was prepared by dissolving $2 \mathrm{~g}$ of $\mathrm{NaCl}$ and $7 \mathrm{~mL}$ of $12 \mathrm{~N} \mathrm{HCl}$ in $1 \mathrm{~L}$ of double distilled water. $20 \mathrm{~mL}$ of the bolus sample taken from the mouth phase was mixed with $20 \mathrm{~mL}$ of artificial gastric fluid that was prepared by mixing $20 \mathrm{~mL}$ of SGFSS with $0.064 \mathrm{~g}$ of pepsin. The mixture was then adjusted to $\mathrm{pH} 2.5$ and incubated at $37^{\circ} \mathrm{C}$ for 2 hours with continuous agitation at $100 \mathrm{rpm}$.

Small intestine phase: $30 \mathrm{~mL}$ of the chyme sample taken from the stomach phase was placed in a water bath at $37^{\circ} \mathrm{C}$ in a beaker and then adjusted to $\mathrm{pH} 7.0$. Then, $1.5 \mathrm{~mL}$ of calcium chloride $(36.7$ $\mathrm{mg} / \mathrm{mL})$ and sodium chloride $(219.1 \mathrm{mg} / \mathrm{mL})$ solution was added. Next, $3.5 \mathrm{~mL}$ of bile extract (53.6 $\mathrm{mg} / \mathrm{mL}$ ) dissolved in buffer solution was added to the sample and the $\mathrm{pH}$ was re-adjusted to 7.0. Lastly, $2.5 \mathrm{~mL}$ of porcine pancreatic lipase $(24 \mathrm{mg} / \mathrm{mL})$ dissolved in buffer solution was incorporated into the mixture. An automatic titration (pH-stat) device (835 Titrando, Metrohm USA Inc., Riverview, FL) was then used to determine the volume of $\mathrm{NaOH}$ solution required to maintain the system at $\mathrm{pH} 7.0$ throughout the incubation period. The amount of free fatty acids released at the small intestine phase was calculated using the following equation:

$$
\% \mathrm{FFA}=100 \times \frac{\mathrm{v}_{\mathrm{NaOH}} \times \mathrm{m}_{\mathrm{NaOH}} \times \mathrm{m}_{\text {lipid }}}{\mathrm{w}_{\text {lipid }} \times 2}
$$

where, $\mathrm{V}_{\mathrm{NaOH}}$ is the volume of titrant consumed in liters, $\mathrm{m}_{\mathrm{NaOH}}$ is the molarity of the $\mathrm{NaOH}$ solution used $(0.1 \mathrm{~N}), \mathrm{m}_{\text {lipid }}$ is the molecular weight of fish oil $(868 \mathrm{~g} / \mathrm{mol}), \mathrm{w}_{\text {lipid }}$ is the weight of oil in the 
digestion system in grams $(0.15 \mathrm{~g})$.

\subsection{Droplet characterization}

The mean particle diameters of the emulsions were measured using a static light scattering instrument (Mastersizer 2000, Malvern Instruments, Westborough, MA). The results are reported as surface-weighted mean diameters $\left(d_{32}\right)$ or volume-weighted mean diameters $\left(d_{43}\right)$. The electrical surface potentials ( $\zeta$-potentials) of the droplets were measured using a particle electrophoresis instrument (Zetasizer Nano ZS Series, Malvern Instruments, Westborough, MA). The emulsions were diluted (1:100) using buffers of the same pH. A confocal microscope (C1 Digital Eclipse, Nikon, Tokyo, Japan) was used to monitor the microstructures of the samples after each phase with a $60 \times$ oil immersion objective. Nile red and fluorescein isothiocyanate (FITC) were used as dyes to stain the lipid and protein parts of the samples, respectively.

\subsection{Data analysis}

All experiments were carried out in triplicate $(n=3)$, with two repeated measurements per sample. Means and standard deviations were then calculated from these values, and then analysis of variance (ANOVA) was carried out using a statistical software package (SPSS Statistics 20, IBM). The Tukey test was employed to determine significant differences amongst samples at a $5 \%$ significance level $(\mathrm{p}<0.05)$.

\section{Results and Discussion}

\subsection{Influence of protein type on particle stability under simulated GIT conditions}

Initially, the impact of the type of protein used to coat the lipid droplets on the gastrointestinal fate of the emulsions under simulated GIT conditions was examined. The mean particle diameter, particle size distribution (PSD), and microstructure of the emulsions was measured after each GIT stage. For the sake of brevity, only the PSD measurements for the whey and pea proteins are shown because the other pulse proteins showed similar results as the pea protein.

Initial systems: Emulsions were prepared using an animal protein (whey) and three plant proteins (pea, lentil, and faba bean). The surface-weighted mean droplet diameters $\left(d_{32}\right)$ were determined after each stage of digestion (Figure 1). The whey protein-stabilized emulsions contained appreciably smaller droplets $\left(d_{32}=129 \mathrm{~nm}\right)$ than the pulse protein-stabilized ones $\left(d_{32}=\right.$ 392 to $485 \mathrm{~nm}$ ). All of the emulsions initially had monomodal PSDs (Figure 2) with relatively small lipid droplets (stained red) evenly dispersed throughout the aqueous phase (Figure 3). The fact that the aqueous phase had a greenish color when observed by confocal fluorescence microscopy (Figure 3), indicated that there were non-adsorbed proteins (stained green) in the aqueous phase. 
The effectiveness of emulsifiers at producing small droplets during homogenization depends on a number of factors: (i) the speed they adsorb to the droplet surfaces; (ii) their saturation surface loads; (iii) their ability to lower the interfacial tension; and, (iv) their ability to generate strong repulsive forces (Jafari et al., 2008; McClements and Gumus, 2016). The minimum droplet diameter that can be produced by a particular emulsifier can be calculated as (McClements, 2015):

$$
d_{\min }=\frac{6 \times \Gamma \times \phi}{C_{s}}=\frac{6 \times \Gamma \times \phi}{(1-\phi) C^{\prime \prime}}
$$

where, $\Gamma$ is the surface load $\left(\mathrm{kg} \mathrm{m}^{-2}\right), \phi$ is the disperse phase volume fraction, $C_{s}$ is the emulsifier concentration in the emulsion $\left(\mathrm{kg} \mathrm{m}^{-3}\right)$, and $C_{s}{ }_{s}$ is the emulsifier concentration in the continuous phase $\left(\mathrm{kg} \mathrm{m}^{-3}\right)$. The surface load of the same proteins was determined in our previous study to be around $1.7 \mathrm{mg} \mathrm{m}^{-2}$ for whey protein, $5.0 \mathrm{mg} \mathrm{m}^{-2}$ for faba bean protein, $5.9 \mathrm{mg} \mathrm{m}^{-2}$ for pea protein, and $10.6 \mathrm{mg} \mathrm{m}^{-2}$ for lentil protein (Gumus et al., 2017). The emulsions used in this study initially contained $10 \% \mathrm{w} / \mathrm{w}$ oil droplets $(\phi \approx 0.1)$ and contained $20 \mathrm{mg} / \mathrm{mL}$ protein in the aqueous phase $\left(\mathrm{C}^{\prime} s\right.$ $=20 \mathrm{~kg} \mathrm{~m}^{-3}$ ). Therefore, the predicted minimum droplet diameters for these emulsions should be around 57, 167, 197, and $353 \mathrm{~nm}$ for whey, faba bean, pea and lentil proteins, respectively. The actual mean droplet diameters $(129,455,392$ and $485 \mathrm{~nm})$ were considerably higher than these theoretical values, which suggests that other factors limited the particle size. For example, the homogenizer pressure used may have been insufficient to break the droplets down to the theoretical limit, the emulsifiers may not have adsorbed fast enough to the droplet surfaces to prevent coalescence, some of the protein molecules may not have adsorbed to the droplet surfaces, or some droplet flocculation may have occurred after homogenization (Jafari et al., 2008; McClements and Gumus, 2016). For example, surface denaturation of globular proteins may occur after adsorption to droplet surfaces, which can increase the surface hydrophobicity of protein-coated droplets, and thereby promote flocculation (Zhai et al., 2013).

Mouth phase: Interestingly, there was a slight decrease in the surface-weighted mean particle diameter $\left(d_{32}\right)$ of the three emulsions stabilized by the pulse proteins when they were exposed to simulated mouth conditions, but a substantial increase for the emulsions stabilized by the whey proteins (Figure 1b). However, there was an increase in the volume-weighted mean particle diameter $\left(d_{43}\right)$ of all the emulsions after exposure to the simulated mouth conditions (Figure 1b). The $d_{43}$ value is more sensitive to the presence of large particles than the $d_{32}$ values, which may account for this effect (McClements, 2015). Indeed, the confocal microscopy images of the different emulsions indicated that they were all highly aggregated in the mouth phase (Figure 3). Droplet aggregation may have occurred due to the presence of mucin (an anionic biopolymer) in the simulated saliva, which has previously been reported to induce depletion and/or bridging flocculation in the mouth phase of GIT models (Sarkar et al., 2009a; Vingerhoeds et al., 2005). Bridging 
flocculation occurs when mucin molecules bind to the surfaces of two or more droplets (Dickinson, 2003), whereas depletion flocculation occurs when the concentration of non-adsorbed mucin molecules in the aqueous phase is high enough to generate a strong osmotic attraction between the droplets (Jenkins and Snowden, 1996). Droplet flocculation may also have been partially the result of electrostatic screening effects, i.e., the accumulation of positively charged counter-ions around the negatively charged lipid droplet surfaces (Dickinson, 2010; Ozturk et al., 2015). The emulsions had bimodal PSDs in the mouth stage (Figure 2), which suggests that only a fraction of the droplets aggregated in the simulated saliva. The fact that the emulsions had a bimodal distribution accounts for the different behaviors of the $\mathrm{d}_{32}$ and $\mathrm{d}_{43}$ values of the emulsions (McClements, 2015).

Stomach phase: After exposure to the stomach phase, the mean particle diameter increased appreciably (Figure 1), and the presence of large aggregates was observed in the particle size distributions (Figure 2) and in the microstructure images (Figure 3) for all emulsions. The observed increase in particle aggregation can be attributed to a number of phenomenon. First, the anionic mucin molecules originating from the simulated saliva may have promoted bridging flocculation of the cationic protein-coated droplets in the acidic gastric fluids (Sarkar et al., 2010; Sarkar et al., 2009b). Second, the pepsin present in the gastric fluids may have partially hydrolyzed the protein coating around the lipid droplets, which would have altered the thickness and charge of the interfacial layer, and therefore reduced the steric and electrostatic repulsion between the droplets (Kenmogne-Domguia et al., 2012; Li et al., 2012). Third, the relatively high ionic strength of the simulated gastric fluids may have reduced the strength of the electrostatic repulsion between the droplets (Sarkar et al., 2010; Sarkar et al., 2009b).

Small intestine phase: After exposure to the small intestine phase, the mean particle diameter remained relatively high (Figure 1), and there was still evidence of large aggregates in the particle size distributions (Figure 2) and microscopy images (Figure 3) for all emulsions. However, the size of these aggregates was significantly lower $(\mathrm{p}<0.05)$ than those observed in the stomach phase for all systems. The composition and structure of the digested materials present in the small intestine phase after lipid digestion is typically highly complex (Yao et al., 2014). Various constituents arising from the emulsions or from the GIT fluids may be present in the digesta, including free fatty acids, monoacylglycerols, peptides, bile salts, phospholipids, enzymes, mineral ions, and undigested lipids and proteins. These constituents can assemble into different types of colloidal particles with different dimensions, morphologies, and aggregation states, including micelles, vesicles, protein aggregates, insoluble calcium salts, and undigested lipid droplets. Consequently, it is difficult to conclusively establish the nature of the particles present in the small intestine fluids after digestion from the light scattering and microscopy measurements. 


\subsection{Influence of protein type on particle charge under simulated GIT conditions}

Changes in the surface potential of the particles in different regions of the GIT were carried out because this provides some valuable information about changes in interfacial composition (Figure 4).

Initial systems: Initially, faba bean, pea, and lentil protein-coated droplets had moderately high negative surface potentials $(-20,-20$, and $-25 \mathrm{mV}$, respectively), while whey protein-coated droplets had considerably more negative values (around $-41 \mathrm{mV}$ ). For electrostatically-stabilized colloidal systems, the magnitude of the $\zeta$-potential on the particles should be greater than about $30 \mathrm{mV}$ to generate repulsive electrostatic forces that are strong enough to overcome attractive van der Waals forces, and thereby prevent particle aggregation over extended periods (Jacobs et al., 2000). Our results therefore suggest that the emulsions containing plant protein-coated droplets may be more susceptible to droplet aggregation than those containing whey protein-coated ones. However, other types of repulsive force may also determine the overall aggregation stability of protein-coated droplets, such as steric repulsion (McClements, 2015). The surface potentials measured in our study are in accordance with those determined for protein-coated lipid droplets in other studies at the same pH (Karaca et al., 2011; Sun and Gunasekaran, 2009).

Mouth phase: After exposure to the mouth phase, there was an appreciable decrease in the magnitude of the surface potential for the whey protein-coated droplets, while the surface potential of the plant protein-coated droplets remained relatively constant (Figure 4). In general, changes in the $\zeta$-potential of particles are due to alterations in either the surface charge density and/or the ionic strength of the surrounding aqueous phase (McClements, 2015). Our results therefore suggest that there was a difference in the change in interfacial composition of the whey and plant protein-coated droplets after exposure to the simulated mouth phase. For both systems, there will have been some electrostatic screening caused by the presence of mineral ions in the simulated saliva (McClements, 2015), but in the case of the whey protein-coated droplets there may have been more mucin molecules adsorbed to their surfaces (Silletti et al., 2010; van Aken et al., 2007; Vingerhoeds et al., 2005). This may have occurred because the whey protein molecules had more exposed cationic groups that could attract anionic groups on the mucin molecules, but further research is needed to confirm this hypothesis.

Stomach phase: After exposure to the stomach phase, the surface potentials of all the emulsions were fairly similar $(+1.1$ to $+1.5 \mathrm{mV})$, with no statistical difference $(\mathrm{p}>0.05)$ amongst them (Figure 4). The simulated stomach phase is highly acidic ( $\mathrm{pH} 2.5)$, and therefore one would have expected the droplets to have a much higher positive $\zeta$-potential that actually observed because this $\mathrm{pH}$ is well below their isoelectric point (Chang et al., 2015). The fact that the measured $\zeta$-potential under 
simulated stomach conditions was actually close to neutral can be attributed to the adsorption of anionic mucin molecules to the surfaces of the cationic protein-coated droplets, leading to charge neutralization (Chang and McClements, 2016; Sarkar et al., 2010). The relatively low charge on the lipid droplets under simulated stomach conditions would account for the high degree of droplet aggregation observed (Figures 1 to 3): the electrostatic repulsion was insufficient to overcome the van der Waals attraction (Dickinson, 2010). In addition, the relatively high ionic strength of the simulated gastric fluids would have led to electrostatic screening effects, which would decrease the magnitude of the surface potential on the droplets (McClements, 2015).

Small intestine phase: After exposure to the small intestine phase, all of the samples contained particles with a strongly negative surface potential (Figure 4). Under the neutral conditions of the simulated intestinal fluids, any proteins remaining should have a strong negative charge because this $\mathrm{pH}$ is well above their isoelectric point. Moreover, the intestinal fluids will contain various other types of anionic species, including free fatty acids, bile salts, and phospholipids, that can form anionic colloidal particles, such as micelles and vesicles (McClements et al., 2009; Singh et al., 2009). The presence of anionic lipid digestion products in all of the samples may account for the fact that they all had fairly similar surface potentials at the end of the small intestine phase. Nevertheless, the $\zeta$-potential of the particles in the digesta resulting from the whey protein emulsions was significantly more negative than that for the plant protein emulsions $(\mathrm{p}<0.05)$, which may have been because the whey proteins were initially more negatively charged at neutral pH (Figure 4).

\subsection{Influence of protein type on in vitro digestion}

If a plant protein is going to be used to stabilize the lipid droplets in emulsion-based delivery systems, then it is important that it does not inhibit the release of the bioactive agents. For this reason, the impact of protein type on the rate and extent of free fatty acid (FFA) release from the different emulsions in the small intestine phase was monitored using a $\mathrm{pH}$-stat method. There was a rapid increase in FFA release during the first 15 minutes of the small intestine phase, with around 85 to $92 \%$ of the lipids being digested in this initial period (Figure 5). From 15 to 120 minutes, there was a further slow increase in the amount of FFAs released from the lipid droplets, with complete lipid digestion occurring by the end of the small intestine phase for all of the samples. These results suggest that there were no major differences in the ability of lipase to hydrolyze the emulsified fish oil in the emulsions stabilized by the different kinds of proteins. This result is markedly different from that of a recent study on the digestion of CLA droplets coated by pea or soy proteins, where it was reported that only about $22-25 \%$ of the FFAs were released by the end of the small intestine phase (Fernandez-Avila et al., 2016). The most likely reason for this apparent discrepancy is that the levels of enzymes and bile salts used in this latter study were insufficient to digest all of the lipids 
and solubilize all the free fatty acids released in the emulsions used (Waraho et al., 2011). The rate of lipid digestion in emulsions is known to increase with decreasing droplet size, because this increases the surface area of the lipid phase exposed to the lipase (Golding and Wooster, 2010; Salvia-Trujillo et al., 2013). The whey protein emulsions initially had smaller mean droplet diameters $\left(d_{32}\right)$ than the plant protein emulsions (Figure 1a), and might therefore have been expected to be digested more rapidly. However, it is the size of the lipid droplets reaching the small intestine, rather than the initial size, that determines rate of lipid digestion, which may account for the fact that the whey protein emulsions were not digested more rapidly than the plant protein emulsions.

The digestion of pulse proteins in foods is often inhibited due to the presence of anti-nutritional factors (ANFs) present in pulses, such as protease inhibitors, lectins, tannins, saponins, and phytates (Liener, 1994). Indeed, it has been reported that the in vitro digestibility of pulse proteins varies between about 60 to $80 \%$ depending on pulse type and processing methods (Chitra et al., 1995). Despite this phenomenon, the lipid droplets coated by all three types of pulse-proteins used in our study were fully digested under simulated GIT conditions (Figure 5). There are a number of possible reasons that may account for this observation. First, anti-nutritional factors are usually eliminated during the isolation procedures used to extract and purify protein ingredients (Fernandez-Quintela et al., 1997). Second, the proteins may have been displaced from the lipid droplet surfaces by bile salts and lipase, and therefore they did not need to be fully digested before the lipids were digested.

\section{Conclusion}

This study has shown that three plant protein isolates (from lentils, peas, and faba beans) could be used to successfully fabricate oil-in-water emulsions containing relatively small fish oil droplets $\left(d_{32}<500 \mathrm{~nm}\right)$. These emulsions could therefore be used as delivery systems for omega-3 polyunsaturated fatty acids, thereby allowing them to be incorporated into aqueous-based functional food and beverage products. The delivery systems stabilized by plant proteins were shown to behave similarly in a simulated gastrointestinal tract (mouth, stomach, and small intestine) as delivery systems stabilized by a commonly used animal protein (whey protein isolate). Moreover, the lipid droplets coated by the plant proteins were completely digested under simulated GIT conditions, and would therefore be expected to fully release the encapsulated omega-3 polyunsaturated fatty acids. These plant proteins may therefore be suitable for the formation of delivery systems for bioactive lipids, although further research is needed to establish their stability under commercial food product conditions, and to determine their sensory attributes.

\section{Acknowledgements}

Cansu Ekin Gumus thanks the Ministry of National Education of Turkey for the International Graduate Fellowship provided for her ongoing doctoral degree. We also thank Jenny Tang and John 
Krill from DSM for useful advice and discussions. This project was partly supported by the USDA, Agriculture and Food Research Initiative Grant, National Institute of Food and Agriculture (201467017-21635), and partly by funding provided by DSM.

\section{Conflict of interest}

The authors declare no conflict of interest.

\section{References}

Baiano, A., (2014). Recovery of Biomolecules from Food Wastes - A Review. Molecules 19(9), 14821-14842.

Boye, J., Zare, F., Pletch, A., (2010). Pulse proteins: Processing, characterization, functional properties and applications in food and feed. Food Res. Int. 43(2), 414-431.

Chang, C., Tu, S., Ghosh, S., Nickerson, M.T., (2015). Effect of pH on the inter-relationships between the physicochemical, interfacial and emulsifying properties for pea, soy, lentil and canola protein isolates. Food Res. Int. 77, 360-367.

Chang, Y.G., McClements, D.J., (2016). Characterization of mucin - lipid droplet interactions: Influence on potential fate of fish oil-in-water emulsions under simulated gastrointestinal conditions. Food Hydrocolloids 56, 425-433.

Chitra, U., Vimala, V., Singh, U., Geervani, P., (1995). Variability in phytic acid content and protein digestibility of grain legumes. Plant Foods Hum. Nutr. 47(2), 163-172.

Dickinson, E., (2003). Hydrocolloids at interfaces and the influence on the properties of dispersed systems. Food Hydrocolloids 17(1), 25-39.

Dickinson, E., (2010). Flocculation of protein-stabilized oil-in-water emulsions. Colloids Surf. B Biointerfaces 81(1), 130-140.

FAO, (2016). Pulses: Nutritious Seeds for a Sustainable Future. FAO.

Fernandez-Avila, C., Arranz, E., Guri, A., Trujillo, A.J., Corredig, M., (2016). Vegetable protein isolate-stabilized emulsions for enhanced delivery of conjugated linoleic acid in Caco-2 cells. Food Hydrocolloids 55, 144-154.

Fernandez-Quintela, A., Macarulla, M.T., Del Barrio, A.S., Martinez, J.A., (1997). Composition and functional properties of protein isolates obtained from commercial legumes grown in northern Spain. Plant Foods Hum. Nutr. 51(4), 331-342.

Genot, C., Kabri, T.H., Meynier, A., (2013). Stabilization of omega-3 oils and enriched foods using emulsifiers, in: Jacobsen, C., Nielsen, N.S., Horn, A.F., Sorensen, A.D.M. (Eds.), Food Enrichment with Omega-3 Fatty Acids, pp. 150-193.

Golding, M., Wooster, T.J., (2010). The influence of emulsion structure and stability on lipid digestion. Curr. Op. Coll. Int. Sci. 15(1-2), 90-101.

Gumus, C.E., Decker, E.A., McClements, D.J., (2017). Formation and Stability of w-3 Oil Emulsionbased Delivery Systems using Plant Proteins as Emulsifiers: Lentil, Pea, and Faba Bean proteins. Food Biophysics Accepted.

Jacobs, C., Kayser, O., Muller, R.H., (2000). Nanosuspensions as a new approach for the formulation for the poorly soluble drug tarazepide. Int. J. Pharm. 196(2), 161-164.

Jacobsen, C., (2015). Some strategies for the stabilization of long chain n-3 PUFA-enriched foods: A review. Eur. J. Lipid Sci. Tech. 117(11), 1853-1866.

Jafari, S.M., Assadpoor, E., He, Y.H., Bhandari, B., (2008). Re-coalescence of emulsion droplets during high-energy emulsification. Food Hydrocolloids 22(7), 1191-1202.

Jenkins, P., Snowden, M., (1996). Depletion flocculation in colloidal dispersions. Adv. Coll. Int. Sci. $68,57-96$ 
Joshi, M., Adhikari, B., Aldred, P., Panozzo, J.F., Kasapis, S., (2011). Physicochemical and functional properties of lentil protein isolates prepared by different drying methods. Food Chem. 129(4), 1513-1522.

Karaca, A.C., Low, N., Nickerson, M., (2011). Emulsifying properties of chickpea, faba bean, lentil and pea proteins produced by isoelectric precipitation and salt extraction. Food Res. Int. 44(9), $2742-2750$.

Kenmogne-Domguia, H.B., Meynier, A., Viau, M., Llamas, G., Genot, C., (2012). Gastric conditions control both the evolution of the organization of protein-stabilized emulsions and the kinetic of lipolysis during in vitro digestion. Food Funct. 3(12), 1302-1309.

Kralova, I., Sjoblom, J., (2009). Surfactants Used in Food Industry: A Review. J. Disp. Sci. Tech. 30(9), 1363-1383.

Lam, R.S.H., Nickerson, M.T., (2013). Food proteins: A review on their emulsifying properties using a structure-function approach. Food Chem. 141(2), 975-984.

Lane, K., Derbyshire, E., Li, W., Brennan, C., (2014). Bioavailability and potential uses of vegetarian sources of omega-3 fatty acids: a review of the literature. Crit. Rev. Food Sci. Nutr. 54(5), 572-579.

Li, J., Ye, A.Q., Lee, S.J., Singh, H., (2012). Influence of gastric digestive reaction on subsequent in vitro intestinal digestion of sodium caseinate-stabilized emulsions. Food Funct. 3(3), 320-326.

Li, Y., Hu, M., McClements, D.J., (2011). Factors affecting lipase digestibility of emulsified lipids using an in vitro digestion model: Proposal for a standardised $\mathrm{pH}$-stat method. Food Chem. 126(2), 498-505.

Liener, I.E., (1994). Implications of antinutritional components in soybean foods. Crit. Rev. Food Sci. Nutr. 34(1), 31-67.

Lordan, S., Ross, R.P., Stanton, C., (2011). Marine Bioactives as Functional Food Ingredients: Potential to Reduce the Incidence of Chronic Diseases. Marine Drugs 9(6), 1056-1100.

Lorente-Cebrian, S., Costa, A.G.V., Navas-Carretero, S., Zabala, M., Martinez, J.A., Moreno-Aliaga, M.J., (2013). Role of omega-3 fatty acids in obesity, metabolic syndrome, and cardiovascular diseases: a review of the evidence. J. Physiology Biochem. 69(3), 633-651.

Lowry, O.H., Rosebrough, N.J., Farr, A.L., Randall, R.J., (1951). Protein Measurement with the Folin Phenol Reagent. J. Biol. Chem. 193(1), 265-275.

Mao, L.K., Miao, S., (2015). Structuring Food Emulsions to Improve Nutrient Delivery During Digestion. Food Eng. Rev. 7(4), 439-451.

Marcone, M.F., Kakuda, Y., Yada, R.Y., (1998). Salt-soluble seed globulins of various dicotyledonous and monocotyledonous plants-I. Isolation/purification and characterization. Food Chem. 62(1), 27-47.

McClements, D.J., (2012). Advances in fabrication of emulsions with enhanced functionality using structural design principles. Curr. Op. Coll. Int. Sci. 17(5), 235-245.

McClements, D.J., (2015). Food emulsions: Principles, practices, and techniques. CRC press.

McClements, D.J., Decker, E.A., Park, Y., (2009). Controlling Lipid Bioavailability through Physicochemical and Structural Approaches. Crit. Rev. Food Sci. Nutr. 49(1), 48-67.

McClements, D.J., Decker, E.A., Weiss, J., (2007). Emulsion-based delivery systems for lipophilioc bioactive components. J. Food Sci. 72(8), R109-R124.

McClements, D.J., Gumus, C.E., (2016). Natural emulsifiers - Biosurfactants, phospholipids, biopolymers, and colloidal particles: Molecular and physicochemical basis of functional performance. Adv. Coll. Int. Sci 234, 3-26.

McClements, D.J., Li, Y., (2010). Review of in vitro digestion models for rapid screening of emulsion-based systems. Food Funct. 1(1), 32-59.

Ozturk, B., Argin, S., Ozilgen, M., McClements, D.J., (2015). Nanoemulsion delivery systems for oil-soluble vitamins: Influence of carrier oil type on lipid digestion and vitamin D-3 bioaccessibility. Food Chem. 187, 499-506. 
Qiu, C.Y., Zhao, M.M., Decker, E.A., McClements, D.J., (2015). Influence of protein type on oxidation and digestibility of fish oil-in-water emulsions: Gliadin, caseinate, and whey protein. Food Chem. 175, 249-257.

Salvia-Trujillo, L., Qian, C., Martin-Belloso, O., McClements, D.J., (2013). Influence of particle size on lipid digestion and beta-carotene bioaccessibility in emulsions and nanoemulsions. Food Chem. 141(2), 1472-1480.

Sarkar, A., Goh, K.K.T., Singh, H., (2009a). Colloidal stability and interactions of milk-proteinstabilized emulsions in an artificial saliva. Food Hydrocolloids 23(5), 1270-1278.

Sarkar, A., Goh, K.K.T., Singh, H., (2010). Properties of oil-in-water emulsions stabilized by betalactoglobulin in simulated gastric fluid as influenced by ionic strength and presence of mucin. Food Hydrocolloids 24(5), 534-541.

Sarkar, A., Goh, K.K.T., Singh, R.P., Singh, H., (2009b). Behaviour of an oil-in-water emulsion stabilized by beta-lactoglobulin in an in vitro gastric model. Food Hydrocolloids 23(6), 1563 1569.

Shao, Y., Tang, C.H., (2016). Gel-like pea protein Pickering emulsions at pH 3.0 as a potential intestine-targeted and sustained-release delivery system for beta-carotene. Food Res. Int. 79, 64-72.

Silletti, E., Vitorino, R.M.P., Schipper, R., Amado, F.M.L., Vingerhoeds, M.H., (2010). Identification of salivary proteins at oil-water interfaces stabilized by lysozyme and betalactoglobulin. Arch. Oral Biology 55(4), 268-278.

Singh, H., Ye, A.Q., Horne, D., (2009). Structuring food emulsions in the gastrointestinal tract to modify lipid digestion. Prog. Lipid. Res. 48(2), 92-100.

Song, M., Fung, T.T., Hu, F.B., Willett, W.C., Longo, V.D., Chan, A.T., Giovannucci, E.L., (2016). Association of Animal and Plant Protein Intake With All-Cause and Cause-Specific Mortality. JAMA Intern Med 176(10), 1453-1463.

Sun, C.H., Gunasekaran, S., (2009). Effects of protein concentration and oil-phase volume fraction on the stability and rheology of menhaden oil-in-water emulsions stabilized by whey protein isolate with xanthan gum. Food Hydrocolloids 23(1), 165-174.

van Aken, G.A., Vingerhoeds, M.H., de Hoog, E.H.A., (2007). Food colloids under oral conditions. Curr. Op. Coll. Int. Sci. 12(4-5), 251-262.

Vingerhoeds, M.H., Blijdenstein, T.B.J., Zoet, F.D., van Aken, G.A., (2005). Emulsion flocculation induced by saliva and mucin. Food Hydrocolloids 19(5), 915-922.

Waraho, T., McClements, D.J., Decker, E.A., (2011). Mechanisms of lipid oxidation in food dispersions. Tr. Food Sci. Tech. 22(1), 3-13.

Wilde, P.J., Chu, B.S., (2011). Interfacial \& colloidal aspects of lipid digestion. Adv. Coll. Int. Sci. 165(1), 14-22.

Yao, M.F., Xiao, H., McClements, D.J., (2014). Delivery of Lipophilic Bioactives: Assembly, Disassembly, and Reassembly of Lipid Nanoparticles, in: Doyle, M.P., Klaenhammer, T.R. (Eds.), Annual Review of Food Science and Technology, Vol 5, pp. 53-81.

Zhai, J.L., Day, L., Aguilar, M.I., Wooster, T.J., (2013). Protein folding at emulsion oil/water interfaces. Curr. Op. Coll. Int. Sci. 18(4), 257-271. 


\section{Tables}

Table 1. Compositional information and color of the pea, lentil and faba bean protein concentrates used in this study (provided by the supplier).

\begin{tabular}{|c|c|c|c|c|c|c|}
\hline & \multicolumn{2}{|c|}{$\begin{array}{l}\text { Vitessence Pulse } \\
1550 \text { (Pea) }\end{array}$} & \multicolumn{2}{|c|}{$\begin{array}{l}\text { Vitessence Pulse } \\
2550 \text { (Lentil) }\end{array}$} & \multicolumn{2}{|c|}{$\begin{array}{l}\text { Vitessence Pulse } \\
3600 \text { (Faba bean) }\end{array}$} \\
\hline Color & \multicolumn{2}{|c|}{ Pale yellow } & \multicolumn{2}{|c|}{ Pale yellow } & \multicolumn{2}{|c|}{ Pale cream, gray } \\
\hline Protein $(\%)$ & \multicolumn{2}{|c|}{55} & \multicolumn{2}{|c|}{55} & \multicolumn{2}{|c|}{60} \\
\hline Fat $(\%)$ & \multicolumn{2}{|l|}{3.1} & \multicolumn{2}{|l|}{3.0} & \multicolumn{2}{|l|}{3.1} \\
\hline $\operatorname{Ash}(\%)$ & \multicolumn{2}{|l|}{5.0} & \multicolumn{2}{|l|}{4.9} & \multicolumn{2}{|l|}{5.0} \\
\hline Moisture (\%) & \multicolumn{2}{|l|}{8.0} & \multicolumn{2}{|l|}{8.0} & \multicolumn{2}{|l|}{9.0} \\
\hline Carbohydrates (\%) & \multicolumn{2}{|l|}{33} & \multicolumn{2}{|l|}{33} & \multicolumn{2}{|l|}{27} \\
\hline - Dietary fiber & \multicolumn{2}{|l|}{14} & \multicolumn{2}{|l|}{13} & \multicolumn{2}{|l|}{11} \\
\hline - Sugars & \multicolumn{2}{|l|}{4.2} & \multicolumn{2}{|l|}{3.2} & \multicolumn{2}{|l|}{2.8} \\
\hline - Other & \multicolumn{2}{|l|}{15} & \multicolumn{2}{|l|}{17} & \multicolumn{2}{|l|}{13} \\
\hline Amino acid composition (\%) & $\begin{array}{l}/ 100 g \\
\text { product }\end{array}$ & $\begin{array}{l}/ 100 \mathrm{~g} \\
\text { total } \\
\text { amino } \\
\text { acids }\end{array}$ & $\begin{array}{l}/ 100 \mathrm{~g} \\
\text { product }\end{array}$ & $\begin{array}{l}/ 100 \mathrm{~g} \\
\text { total } \\
\text { amino } \\
\text { acids }\end{array}$ & $\begin{array}{l}\text { /100g } \\
\text { product }\end{array}$ & $\begin{array}{l}/ 100 \mathrm{~g} \\
\text { total } \\
\text { amino } \\
\text { acids } \\
\end{array}$ \\
\hline Arginine & 3.8 & 8.9 & 3.5 & 8.3 & 4.8 & 10.1 \\
\hline Histidine & 1.2 & 2.8 & 1.1 & 2.6 & 1.4 & 3.0 \\
\hline Isoleucine & 1.9 & 4.4 & 2.2 & 5.2 & 2.2 & 4.7 \\
\hline Leucine & 3.7 & 8.7 & 3.7 & 8.8 & 3.9 & 8.3 \\
\hline Lysine & 3.6 & 8.4 & 3.6 & 8.6 & 3.4 & 7.2 \\
\hline Methionine & 0.5 & 1.2 & 0.4 & 1.0 & 0.4 & 0.8 \\
\hline Phenylalanine & 2.3 & 5.4 & 2.6 & 6.2 & 2.2 & 4.7 \\
\hline Threonine & 1.7 & 4.0 & 1.7 & 4.0 & 1.9 & 4.0 \\
\hline Valine & 2.3 & 5.4 & 2.3 & 5.5 & 2.5 & 5.3 \\
\hline Alanine & 2.1 & 4.9 & 1.9 & 4.5 & 2.2 & 4.7 \\
\hline Asparagine & 5.4 & 12.6 & 5.4 & 12.8 & 5.5 & 11.6 \\
\hline Cysteine & 0.6 & 1.4 & 0.4 & 1.0 & 0.6 & 1.3 \\
\hline Glutamine & 7.6 & 17.8 & 7.6 & 18.0 & 9.2 & 19.5 \\
\hline Glycine & 2.0 & 4.7 & 1.8 & 4.2 & 2.4 & 5.1 \\
\hline Serine & 2.1 & 4.9 & 2.2 & 5.2 & 2.6 & 5.5 \\
\hline Tryptophan & 0.5 & 1.2 & 0.4 & 1.0 & 0.5 & 1.1 \\
\hline Tyrosine & 1.4 & 3.3 & 1.3 & 3.1 & 1.5 & 3.1 \\
\hline Non-protein nitrogen & 8.7 & N/A & 9.3 & N/A & 8.9 & N/A \\
\hline
\end{tabular}




\section{Figure Captions}

Figure 1a: Influence of gastrointestinal tract stage and emulsifier type on the mean particle diameter of $\mathrm{O} / \mathrm{W}$ emulsions. Different lower case letters represent significant differences $(\mathrm{p}<0.05)$ between different samples in a given in vitro digestion stage.

Figure 1b: Volume-weighted mean particle diameter of O/W emulsions in different GIT stages.

Different lower case letters represent significant differences $(\mathrm{p}<0.05)$ between different samples in a given GIT stage.

Figure 2: Particle size distribution of $\mathrm{O} / \mathrm{W}$ emulsions stabilized by pea protein (white symbols) or whey protein (black symbols) after exposure to different stages of the simulated GIT.

Figure 3: Influence of emulsifier type and GIT stage on the microstructure of $\mathrm{O} / \mathrm{W}$ emulsions exposed to different GIT stages.

Figure 4: Influence of gastrointestinal tract stage and emulsifier type on the particle charge of O/W emulsions. Different lower case letters represent significant differences $(\mathrm{p}<0.05)$ between different samples in a given GIT stage.

Figure 5: Release of free fatty acids from O/W emulsions stabilized by different emulsifier types during exposure to simulated small intestine conditions. 


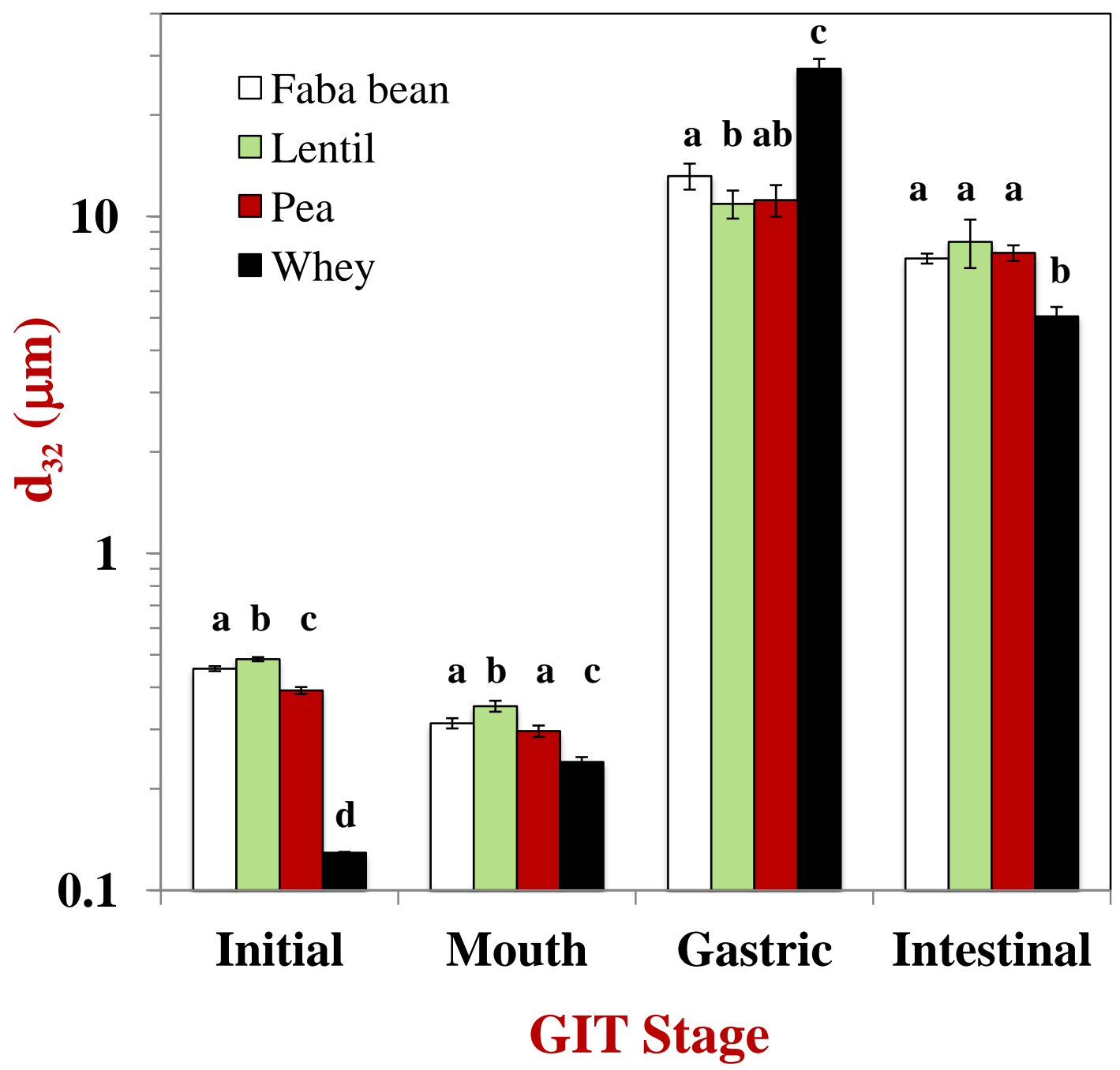

Figure 1a: Influence of gastrointestinal tract stage and emulsifier type on the mean particle diameter of O/W emulsions. Different lower case letters represent significant differences $(\mathrm{p}<0.05)$ between different samples in a given in vitro digestion stage. 


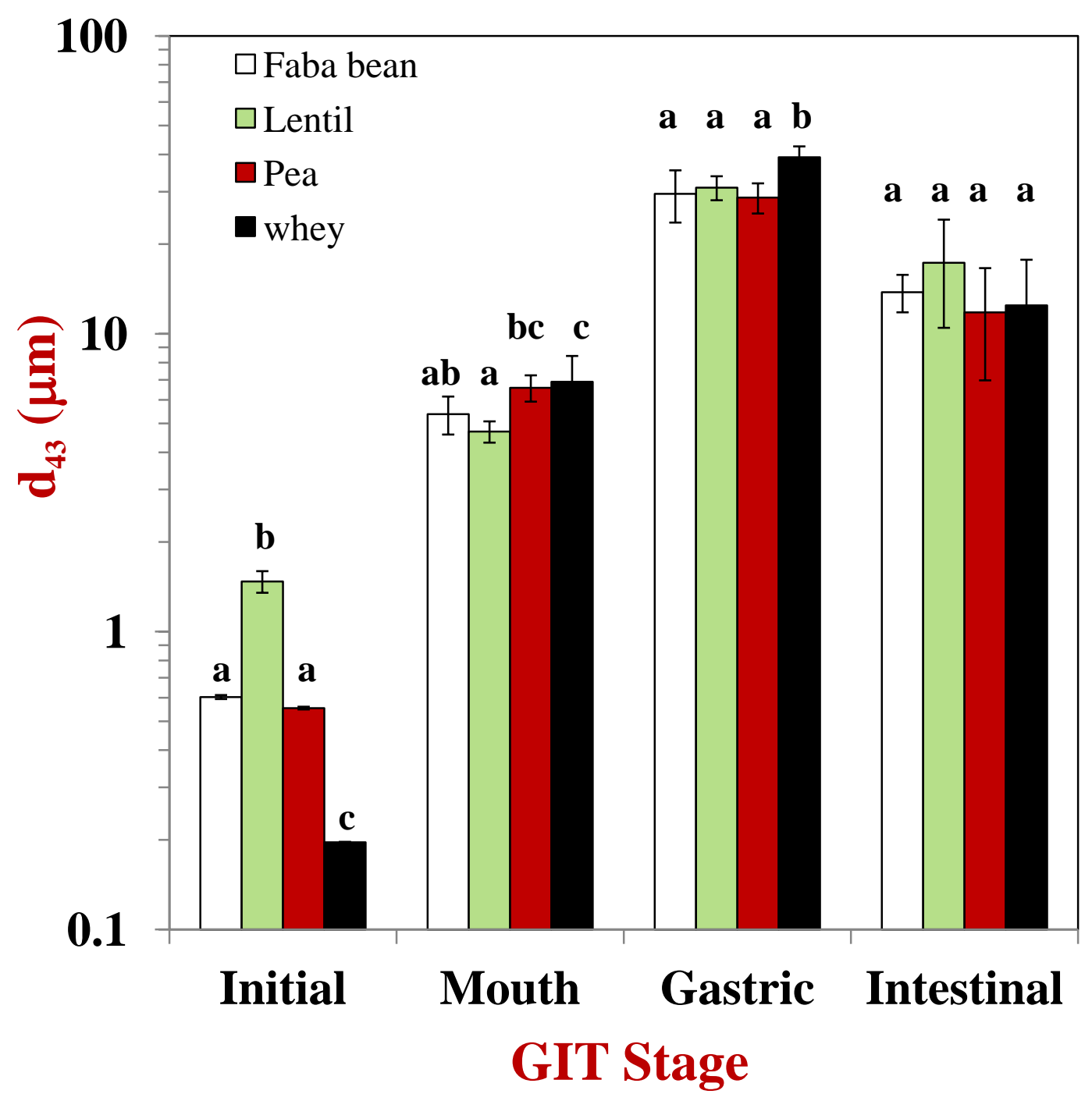

Figure 1b: Volume-weighted mean particle diameter of O/W emulsions in different GIT stages. Different lower case letters represent significant differences $(\mathrm{p}<0.05)$ between different samples in a given GIT stage. 


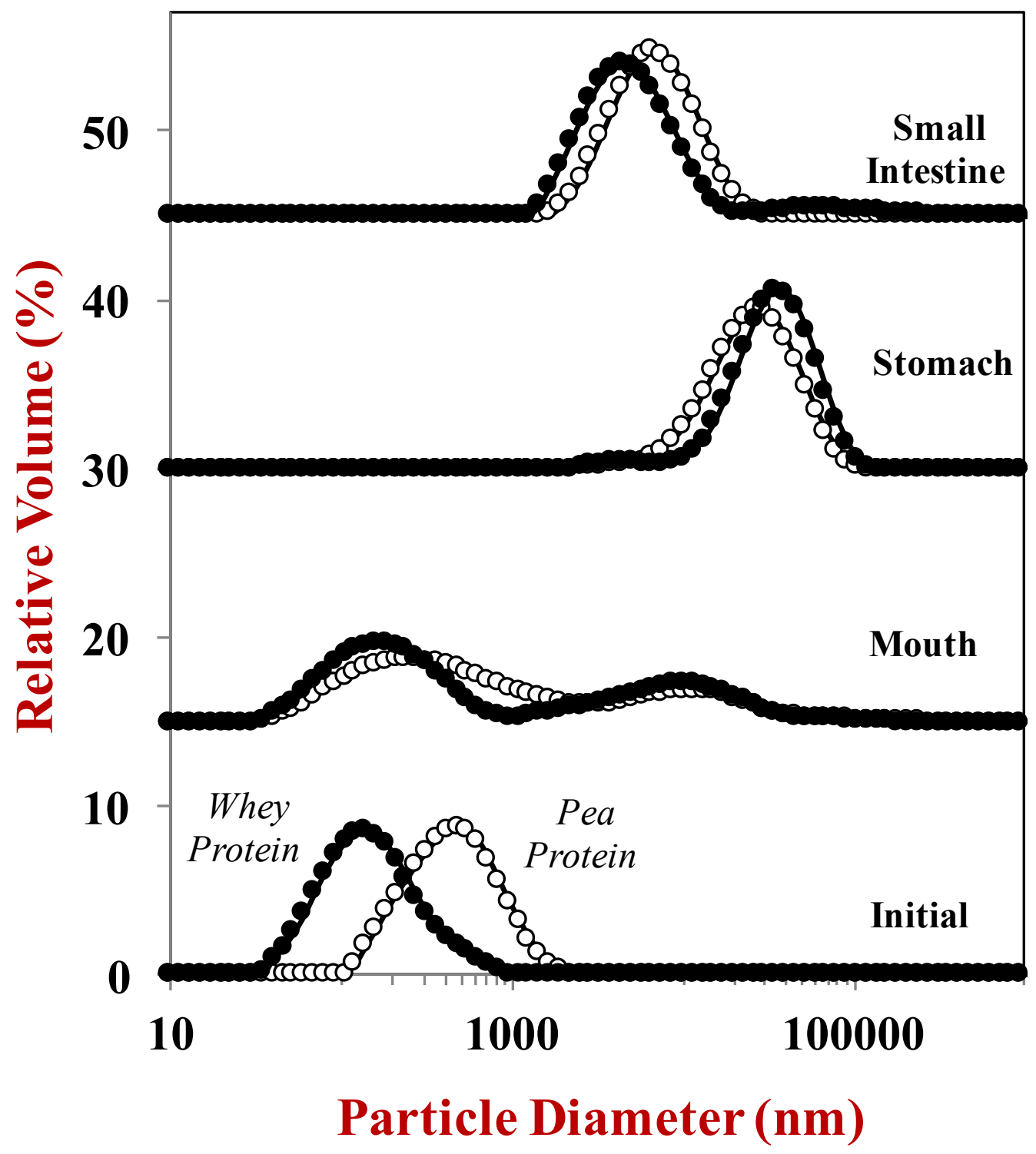

Figure 2: Particle size distribution of $\mathrm{O} / \mathrm{W}$ emulsions stabilized by pea protein (white symbols) or whey protein (black symbols) after exposure to different stages of the simulated GIT. 


\section{Faba bean}
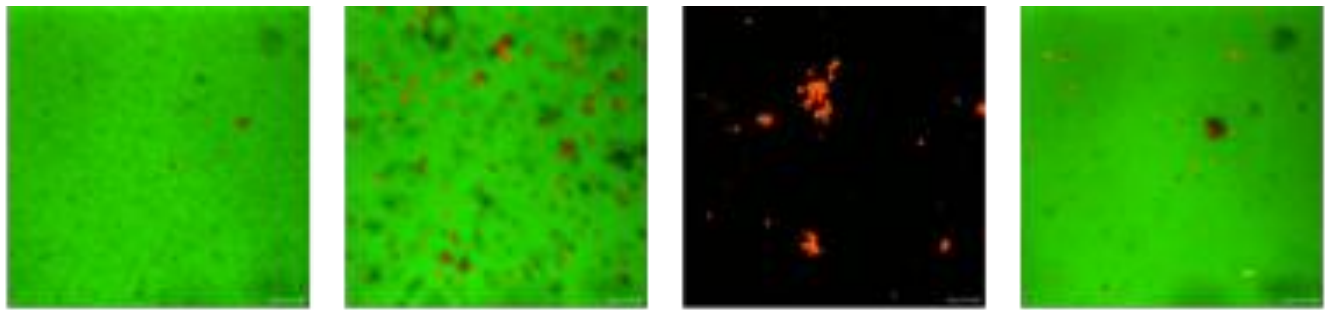

Lentil
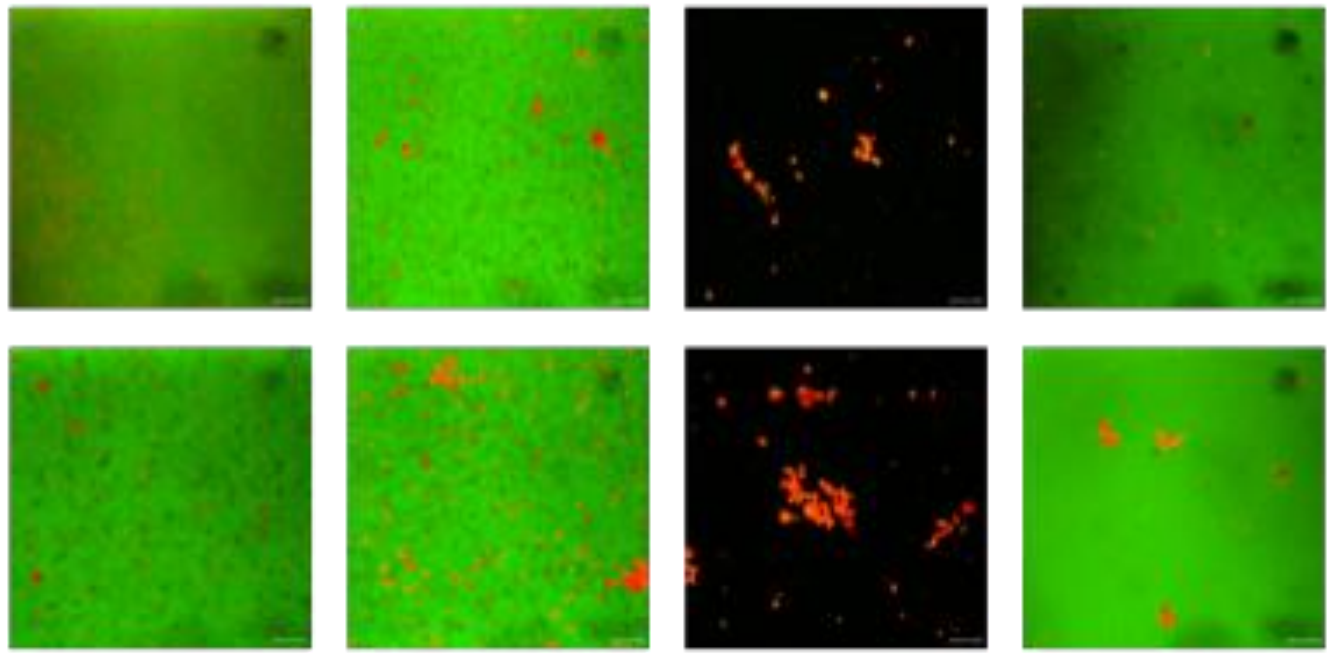

Pea
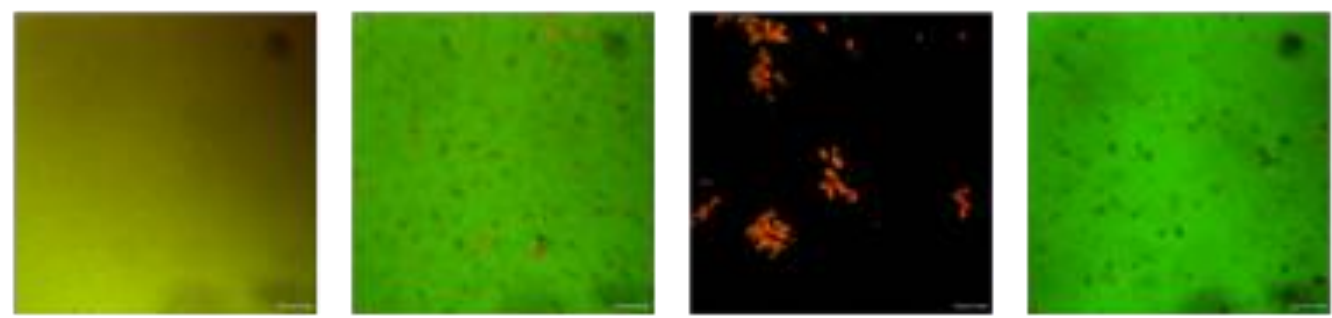

\section{Initial}

Mouth

Stomach

Intestine

Figure 3: Influence of emulsifier type and GIT stage on the microstructure of O/W emulsions exposed to different GIT stages. 


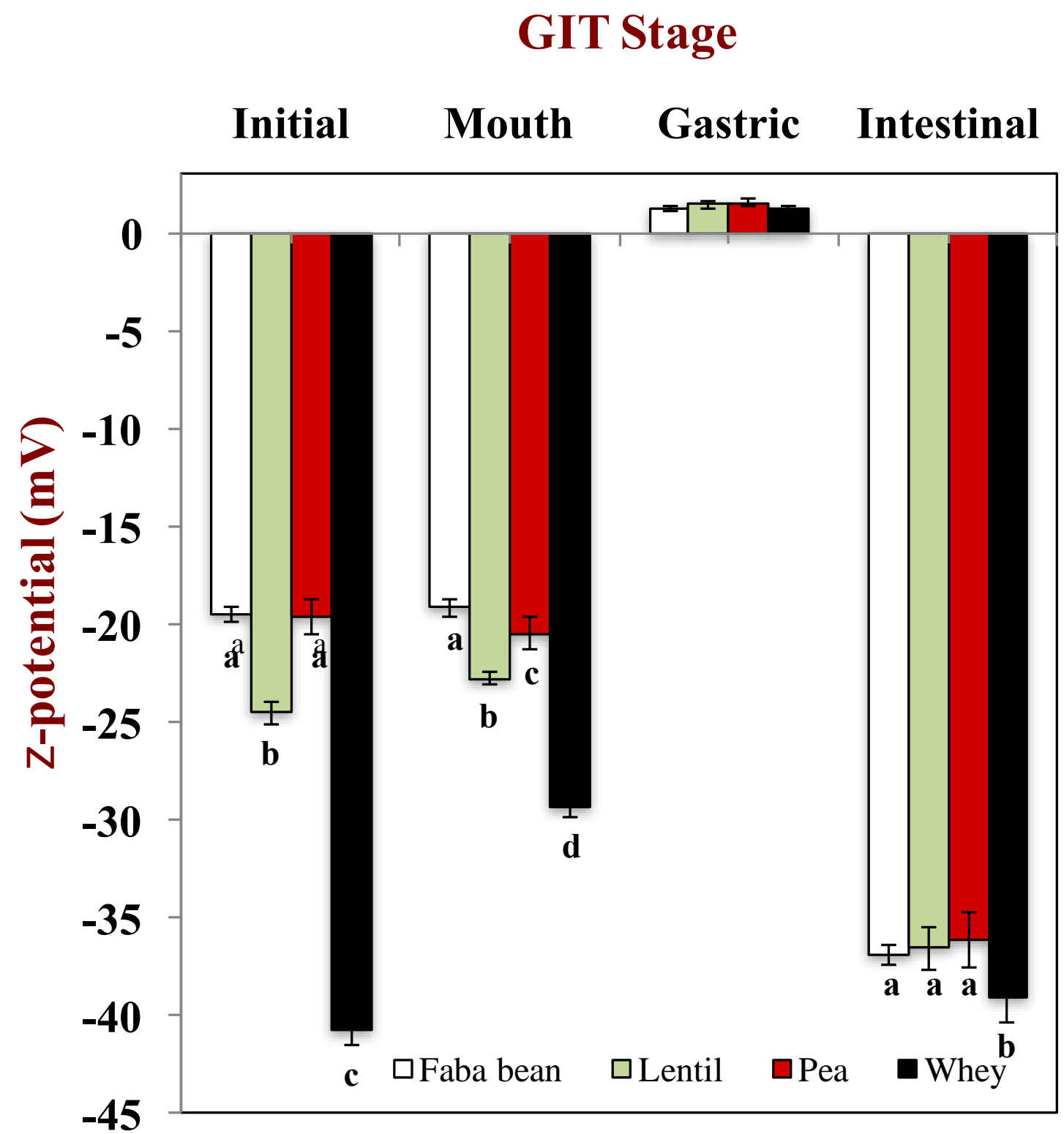

Figure 4: Influence of gastrointestinal tract stage and emulsifier type on the particle charge of O/W emulsions. Different lower case letters represent significant differences $(p<0.05)$ between different samples in a given GIT stage. 


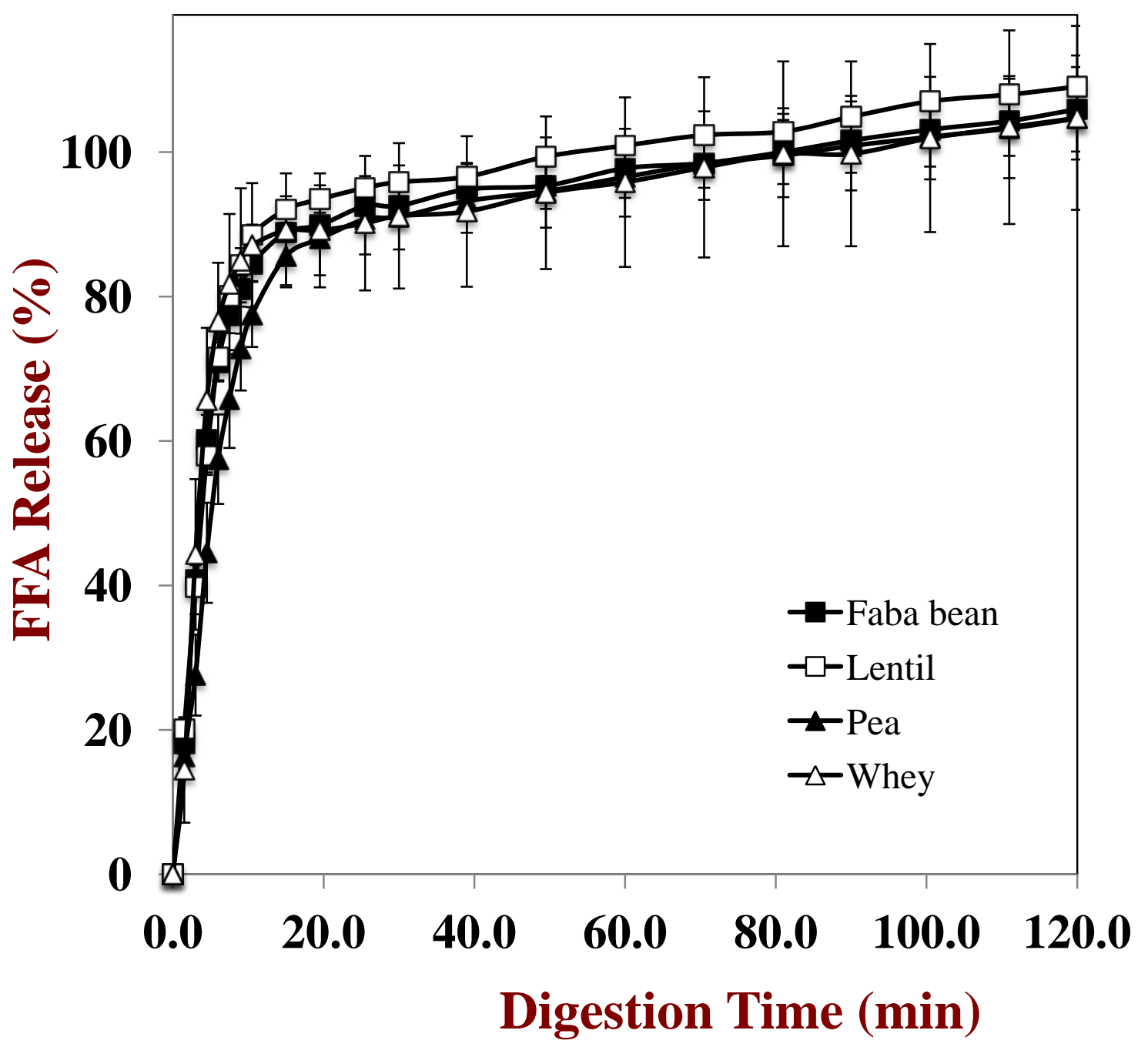

Figure 5: Release of free fatty acids from $\mathrm{O} / \mathrm{W}$ emulsions stabilized by different emulsifier types during exposure to simulated small intestine conditions. 